EPiC Series in Computing
Volume 78, 2021, Pages 49-58
Proceedings of the European Univer-
sity Information Systems Conference 2021

\title{
La Collection Numérique: A way to (better) understand French HigherEd digital
}

\author{
Bertrand Mocquet $^{1,2^{*}}$ and David Rongeat ${ }^{1}$ \\ ${ }^{1}$ Agence de Mutualisation des Universités et Etablissements (AMUE), France \\ ${ }^{2}$ Laboratory MICA, Bordeaux Montaigne University, France \\ Bertrand.Mocqueteamue.fr, David.Rongeateamue.fr
}

\begin{abstract}
We propose to give a French experience feedback on a problem known to all of us in Europe in Higher Education: strategic decision support for HigherEd digital. We hypothesize that one of the elements of success in terms of decision making is the understanding of the HigherEd digital object, especially the impact. We propose to relate the experience of La Collection Numérique in the AMUE (the French shared-services agency for universities and other higher education and research Institutions) and how it contributes to better understand our digital? La Collection Numérique is a tool for prospective watch that deals with a given topic, in a systemic way, its interaction with the university's digital. It's a magazine proposed every two months to the French HigherEd community, and more particularly to the decision makers of Universities and Schools: Presidents, Directors, Digital Vice President, CIO, business departments.
\end{abstract}

Keywords: prospective watch, digital technology, higher education, digital strategy, infocommunication device.

* $\underline{\text { https://orcid.org/0000-0002-9406-4587 }}$ 


\section{Introduction}

In this paper, we report on the implementation of a new info-communication system, every two months, published since January 2019 under the name La Collection Numérique, (Amue, 2019). We hypothesize that through its mediation role (Akrich, 1993; de Jouvenel, 1999; Gardiès, 2012; Mucchielli, 1995), it would contribute to a better understanding of university digital technology for managers and middle managers, the decision-makers, in universities and institutions. In what way does this device (Peeters \& Charlier, 1999) contribute to a better understanding of the French HigherEd digital? What choices have been made? What singularity? How has it become professionalized, and finally, what perception do certain stakeholders have of its effect? And finally, how to accompany stakeholders in the evolution of digital technology in universities? We share our experience hoping to create fork in another land.

\subsection{French Higher Education and digital culture of decision-makers}

In France, today 2.6 million students, many French universities and higher education and research establishments have begun the process of digital transformation, with teams that started out as pioneers, and are now being joined by a greater number of players within the organization, both members and users (Mocquet, 2020).

To limit the double risk, the exhaustion of the pioneers and the financial loss due to unwise choices, we believe that the teams at the helm of institutions should have a better understanding of digital technologies in order to anticipate and accompany their induced changes (Godet, 1989).

This digital culture of those who decide is not easily acquired and we count few existing devices to date in the context of the digital transformation to support university decision-makers: the challenge is to develop a learning community (Querrien, 2013) and a better understanding of technical objects (Simondon, 1958) (Bachimont, 2010).

\subsection{Amue : a stakeholders of the French HigherEd digital}

Amue (shared-services agency for universities and other higher education and research Institutions) provides higher education institutions with IT solutions, training and expertise in their various field of activity.

It organizes cooperation among its members and supports their joint action to improve the quality of their management, monitoring and decision making:

+ Development and optimization of co-constructed IT solutions (shared costs)

+ Professionalization and skills development of higher education staff through training

+ Cost reduction through central purchasing

+ Accompanying performance improvement by providing expertise and regulatory information watch.

Amue builds a collective approach with the experts of its 180 members, from the definition of the needs to the choice and the development of IT solutions, the construction of the training offer or procurement.

There are similar organizations in Europe with different scopes of action, for example and not exhaustively: JISC and UCISA (UK), HIS (DE), OCU and Sigma (SP) and Cineca (IT)... 


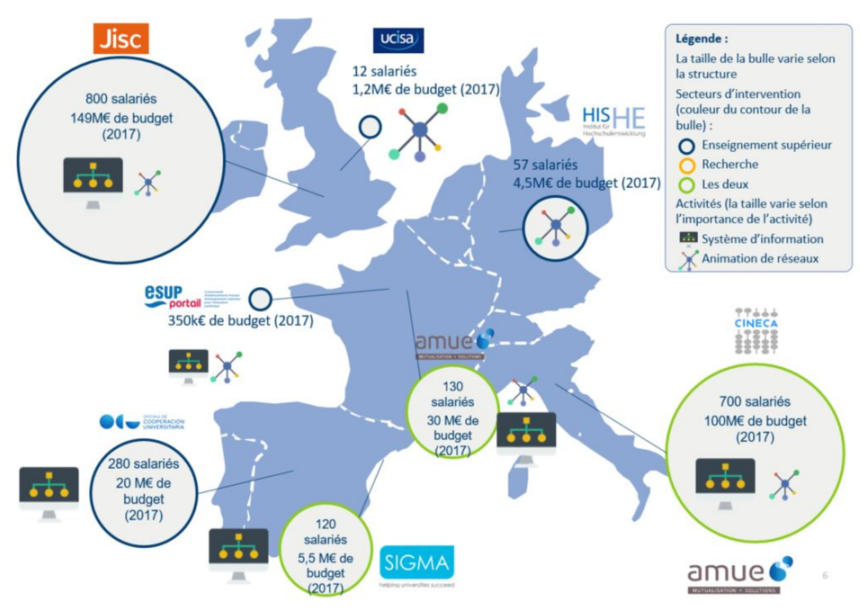

Figure 1 : European mapping of mutualization organizations. Source Amue

\subsection{La Collection Numérique: Why and What?}

La Collection Numérique, a bi-monthly info-communication device (Couzinet, 2011), is the result of an internal prospective watch (Antoine, 1992) and a co-editing with members of Higher Education and Research wishing to promote their new digital technology tools, or to give their point of view or feedback on the subject covered. It aims to initiate reflections, to raise awareness of the governance, of a future vision of the digital Higher Ed; an objective to prepare minds for future developments. One of the objectives is to draw attention to the dynamics of change in university digital technology, and to understand how it is evolving. We try to choose themes that cover the range of current digital issues in France and abroad.

The Amue offers it to its members but also to all, in open license, Creative Commons 4.0 NcBySa, on topics related to digital education and research. One of the issues has been translated for Eunis, it concerns open data, and can be consulted by English-speaking readers.

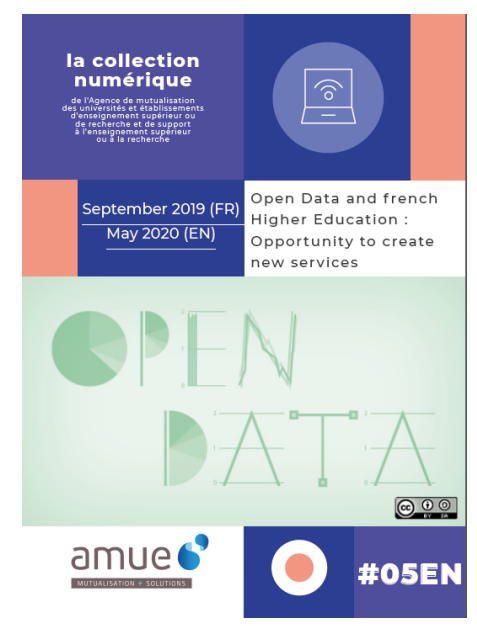

Figure $2: \mathrm{N}^{\circ} 05$ bis - Open Data and french Higher Education : Opportunity to create new services, mai 2020 translated into English for an EUNIS seminar 
The Amue offers it to its members, but also to everyone in free access, on topics related to Higher Ed digital : the first five issues are entitled "prospective watch", "chatbots", "mutualization and coconstruction", "the cloud", "open data", and "testimonials of digital uses".These themes are dealt with functionally, technically, strategically within Higher Education but also outside the university system. It is about digital technologies close to the management information system but also about the effect of this management information system on the digital ecosystem (and vice versa). Issues that are more oriented towards changes in society (the place of women in the digital world, digital Europe, digital sobriety/GreenIT, etc.) present observed movements, trends, and societal demands that interact with HigherEd digital. Each issue is based on a profoundly systemic approach, in which we recognize the influence of internal and external factors in the functioning of the university system. Here, digital is considered as a profession in a logic of stakeholders. The point of view of the editors, of the Amue or of the universities or institutions, is to highlight new uses in certain universities, and to propagate their visibility. It is also a question of offering a strategic analysis of certain concepts such as Artificial Intelligence, Big Data, connected objects, new ways of working, etc... by insisting on uses that we consider relevant for Higher Education and research. Issues more focused on societal changes (women's place in the digital world, Europe, digital sobriety, etc.) present observed movements, trends, and societal requirements that interact with the university digital environment.

Distributed to the 20,000 subscribers of the Amue newsletter and relayed on professional social networks, the first 14 issues deal with contemporary university digital issues.

\begin{tabular}{|l|l|}
\hline $\begin{array}{l}\mathrm{N}^{\circ} 00 \text { - Prospective watch a mechanism for mobilizing } \\
\text { Higher education stakeholders, January 2019 (FR) }\end{array}$ & $\begin{array}{l}\mathrm{N}^{\circ} 01 \text { - Chatbots at the crossroads of intelligence: Uses, } \\
\text { technologies and HigherEd, January 2019 (FR) }\end{array}$ \\
\hline $\begin{array}{l}\mathrm{N}^{\circ} 02 \text { - Mutualization and co-construction: When digital and } \\
\text { organizations interact on a daily basis, March 2019 (FR) }\end{array}$ & $\begin{array}{l}\mathrm{N}^{\circ} 03 \text { - Materiality of the cloud - Impacts on our information } \\
\text { systems and organizations, May 2019 (FR) }\end{array}$ \\
\hline $\begin{array}{l}\mathrm{N}^{\circ} 04 \text { - Multiple and varied digital uses in the context of } \\
\text { Higher Education and Research, July 2019 (FR) }\end{array}$ & $\begin{array}{l}\mathrm{N}^{\circ} 05 \text { - Open Data and HigherEd, opportunity to create new } \\
\text { services, September 2019 (FR) }\end{array}$ \\
\hline $\begin{array}{l}\mathrm{N}^{\circ} 05 \text { bis - Open Data and French Higher Education : } \\
\text { Opportunity to create new services, May 2020 (EN) }\end{array}$ & $\begin{array}{l}\text { No.06 - Higher Education seen through the prism of } \\
\text { university data, November 2019 (FR) }\end{array}$ \\
\hline $\begin{array}{l}\mathrm{N}^{\circ} 07 \text { - Buildings and digital - changes and new challenges, } \\
\text { January 2020 (FR) }\end{array}$ & $\begin{array}{l}\mathrm{N}^{\circ} 08 \text { - Women, digital and Higher Education, March 2020 } \\
(\mathrm{FR})\end{array}$ \\
\hline $\begin{array}{l}\text { No.09 - Accessibility of digital university, May 2020 (FR) } \\
\mathrm{N}^{\circ} 11 \text { - Academic and digital Europe, October 2020 (FR) }\end{array}$ & $\begin{array}{l}\text { No.10 - Multiple and varied digital uses in the context of } \\
\text { Higher Education and Research, July 2020 (FR) }\end{array}$ \\
\hline $\mathrm{N}^{\circ} 13$ - Long live open source! February 2021 (FR) & $\begin{array}{l}\mathrm{N}^{\circ} 14-\text { Simplification and automation of procedures, April } \\
2021 \text { (FR) }\end{array}$ \\
\hline
\end{tabular}

Table 1: The 14 existing issues available http://www.amue.fr/systeme-dinformation/metier/la-collectionnumerique/

\subsection{La Collection Numérique: a piece of prospective strategy}

Monitoring the future at Amue is the role of all the players: management, IT project management, and all the agents.

As far as our work is concerned, this forward-looking information watch mainly consists of identifying and analyzing various subjects (societal, usage or technological) that may have an impact on the management of Higher Education and Research institutions, their organizations, their 
information systems and/or the management applications offered by Amue. It is an anticipation mechanism that proposes scenarios to the Management of the Amue. This is our prospective strategy.

This is a constant, regular activity whose simplified process is described below: INPUTS $>$ ANALYSIS $>$ OUTPUTS

The scope of our prospective watch is defined according to the Amue's scope of intervention, its strategic developments, societal developments and developments in Higher Education and Research institutions, as well as trends in technologies, new uses and digital practices: these are the INPUTS. This set of information feeds our prospective strategy, which is updated regularly and is then broken down into themes to which we pay particular attention. These themes are treated functionally, technically, strategically. They are subjects that can have an impact on the digital environment of the HigherEd and the management information system of institutions or the Amue's software offer in the short, medium or long term. The different sources that allow to feed this work are : 1 /for the formal part, a few examples: professional networks, IT magazines, HigherEd press, IT service providers, consultation of research works, websites specialized on a subject, national or international congresses and seminars (Eunis, Educause).... 2/ for the informal part, it is about exchanges and discussions with colleagues, contacts with other state operators, service providers (software editors, service companies), specialists or experts of a subject... We collect information in different ways: exchanges with stakeholders of institutions or national networks (business, IT,..), exchanges with IT companies, participation in seminars, webinars, search for information on the Internet, reading of press or specialized media, specialized newsletters or consultation of research works

The regular exploitation and analysis of these different sources allows us to capitalize, by subject, useful or necessary information for our monitoring: trends, definitions, opinions on a technology, key players, architectural elements, experiences, uses, popularization elements, significant projects,... The ANALYSIS of these various subjects defines those which deserve a particular attention, an in-depth study. The choice of these topics is made by measuring the potential impact on HigherEd IT, through exchange with our community and our management. This is one of the bases for defining the annual program of La Collection Numérique.

The result of this monitoring system takes several forms of dissemination, the OUTPUTS: 1/Seminars or thematic webinars led by Amue (e.g. a thematic day on Open Data, a webinar on the organizational impacts of telework, ...), 2/Interventions in seminars or symposiums organized by other organizations (e.g., the topic of chatbots in a seminar on artificial intelligence, an intervention on Open Data during a bootcamp for digital vice-presidents of universities), 3/documents, meetings, for Amue governance to amend its strategy or for IS projects to further study topics identified by the information watch and anticipate their impact 4/Finally, La Collection Numérique.

La Collection Numérique is one of the results of monitoring work, an object that attracts attention because of its form and wide distribution. It is complementary to other dissemination devices.

\subsection{La Collection Numérique: how it's made?}

La Collection Numérique is one of the elements for sharing the information watch on digital uses in Higher Education. It aims to detect them, to share testimonials that enhance existing practices, to project the stakeholders ... but also to enrich Amue's point of view on these societal, organizational, usage or technological topics of digital university.

In short, we must open our ears, be one step ahead, take stock of the situation and offer readers a reflection on the subject or field, as opinions may differ within the same collection.

The editorial line was immediately obvious to us: it is based on existing research work that allows us to treat a theme from a strategic, technological and societal point of view through a systemic approach, from macro to micro.

More globally, it is the choice of themes, resulting from our oversight that allows us to make our participation proposals to colleagues or relations. We also target stakeholders outside the Higher 
Education to have the most complete view possible of the subject and to capitalize on experiences or analyses outside our environment. We try to cover the topic comprehensively and are generally very well received by the authors we solicit.

Annually, from the list of topics to be deepened from the monitoring process, we establish the list of the next 6 issues, for the coming academic year. The in-depth work on each topic begins on average 4 to 6 months before the publication of the issue.

For each issue on a given theme, 3 months before the publication of the issue, a work on the summary is carried out: identification of the articles to be written, the stakeholders to be solicited, the sources of information.

Two months before the issue's planned publication, the table of contents is validated by the director of the Amue, who is the publishing director of La Collection Numérique. This summary includes, for each article, the subject to be covered, the author (or authors) to be contacted and the section in which the article will be placed.

At this stage, the authors are asked to produce a text of about one A4 page (3500 characters) with one or more illustrations. The article is requested for a date of one month before the release of the issue. We do not intervene on the articles proposed by the authors.

Once all the articles are received, they are provided to our communication team which takes care of the formatting before distributing the issue to the 20,000 subscribers of the Amue newsletter and relaying this distribution on our social networks.

\section{Methods}

Our approach is multidisciplinary, characteristic of Information and Communication Sciences. We base our epistemological approach on an explanatory posture that "aims to highlight the relationships between phenomena through the observation of regular sequences" (Schurmans, 2009, p.91).

"Founded on the project resulting from the intentional interaction of a subject on an object" (Piaget, 1970), our epistemology is constructivist, a "conception of knowledge understood as an active process before being understood as a finished result" (Piaget, 1970, p.75). The idea here is indeed "to participate in the construction of the perceived reality of the stakeholders" (Bertacchini, 2009) in order to (make) understand and perhaps allow for a transposition in another country.

\subsection{Survey by questionnaire}

For the survey, we recall that "numerical data provide evidence of a quantitative nature, while nondigital data provide evidence of a qualitative nature" (Yin, 1989). We choose to implement an online survey among the members concerned. Our population in the statistical sense is made up of Amue members who were contacted by different means - emails, mailing lists, social networks - during the month of May 2021. Our collection device is based on a questionnaire proposed online through the training platform. We chose to create the form using the Sphinx tool to facilitate access to participants from invitations made online.

The questionnaire, which takes about five minutes to complete, consists of 11 questions, most of which are closed-ended and allow for one or more answers. It is organized in two sections: 1/you are a reader, 2/you are an author. Within these two sections, the main variables studied are distributed around the quality of the system and the measurement of feelings.

Our sample is of a voluntary nature, and it is obviously impossible to attempt any generalization, which would be totally hazardous. Based on the online survey, 84 questionnaires were completed.

We are aware that the sample size is far too small to allow for a precise and generalizable statistical study. What we are interested in here are the trends that will appear in the results. 


\subsection{Analysis of the issues}

We have made an analysis of each issue by focusing on the number of articles per category, type of authors (internal/external) (status).

\section{Results}

\subsection{By the survey}

Readers : The survey respondents (60\% men, 39\% women and 1\% doesn't say it) come from all HigherEd professions: engineering or technical staff (50\%), teachers/researchers $(20 \%)$, administrative staff $(13 \%)$, teachers $(4 \%)$, researchers $(2 \%)$ and others $(11 \%)$. Their age group is $46-55$ years $(38 \%)$, $56-65$ years $(31 \%), 36-45$ years $(21 \%)$, 66-+ years $(5 \%), 26-35$ years $(4 \%)$ and $18-25$ years $(1 \%)$. Among the readers, $71 \%$ have already recommended reading La Collection Numérique.

Types of reading: Among the sample, 31\% are university decision-makers who read the Collection numérique to find, in order of citation, intelligence, strategy and insight into the issue's subject. In terms of reading modalities (several answers possible), people read at work (79\%), at home (40\%), on the road and other ( $8 \%)$. Readers admit (several answers possible) to selecting the articles that interest them (78\%), reading diagonally $(38 \%)$ and $6 \%$ read the entire magazine.

The categories : the 8 headings were ranked in order of importance according to the readers. We find Issues \& Strategy tied with Uses as the most cited category (89\%), followed by Testimonials (84\%), Overview (80\%), Research (73\%) and International Testimonials (69\%). The two headings Return on $(69 \%)$ and Big Ears (64\%) are significantly less cited as important by readers.

What characterizes La Collection Numérique : It was proposed to give three key words to characterize the journal. Among the first four words mentioned, we find information watch (16), innovation (13), experience (13) and information (8) (Figure 3). We note the positive qualifiers of rich, appropriate, clear, serious, relevant, precise and no qualifiers with a negative connotation.

Only $18 \%$ of readers have taken or are taking concrete action on a topic addressed by an issue after reading it.

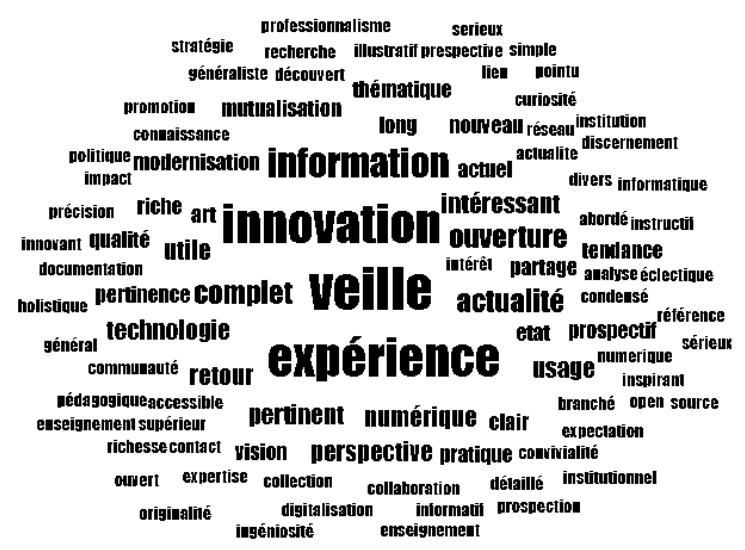

Figure $3: 3$ keywords per person

Authors : $94 \%$ of authors recommend reading the collection numérique in which they have written, mainly through personal distribution channels such as email (the majority) and social networks (Twitter, Linkedin and Facebook) 


\subsection{By La Collection Numérique issues}

The format: Following an audit, a change of format was implemented starting with issue 7: improvement of the form but above all organization of each issue around sections: editorial, issues and strategy, overview, Higher Education testimonies, research, testimonies and feedback from society, international, technology.

In figures: these first 14 issues represent: 468 pages, 300 articles and 250 writers (some of whom contributed several articles) outside the Amue teams.

Authors' contributions: The first issue (chatbot) was mainly produced by Amue. As the issues progressed, the proportion of contributions from outside the Amue increased to an average of $63 \%$, with a peak of $85 \%$ for the second issue on uses. A total of 250 authors contributed to at least one article.

The number of external authors has evolved to an average of 19 per issue. We have observed an increase in co-authorship, with some articles being written by a department manager and the team members who were responsible for the subject presented.

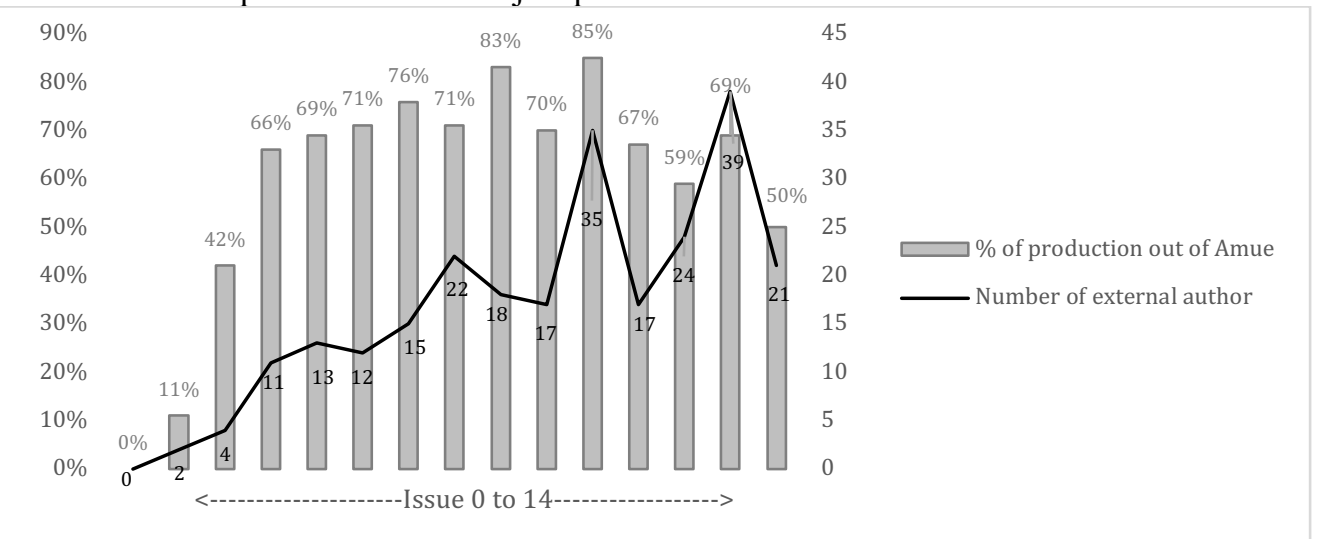

Figure 4 : Evolution of author types

Articles by topic: Articles on technologies are rare, this coming from the fact that on prospective subjects the production of a technical article can be risky but also that the numbers oriented on the societal evolutions (place of the women in the numerical, Europe...) are not concerned by this heading.

Experience sharing and testimonials from the Higher Education are in the majority.

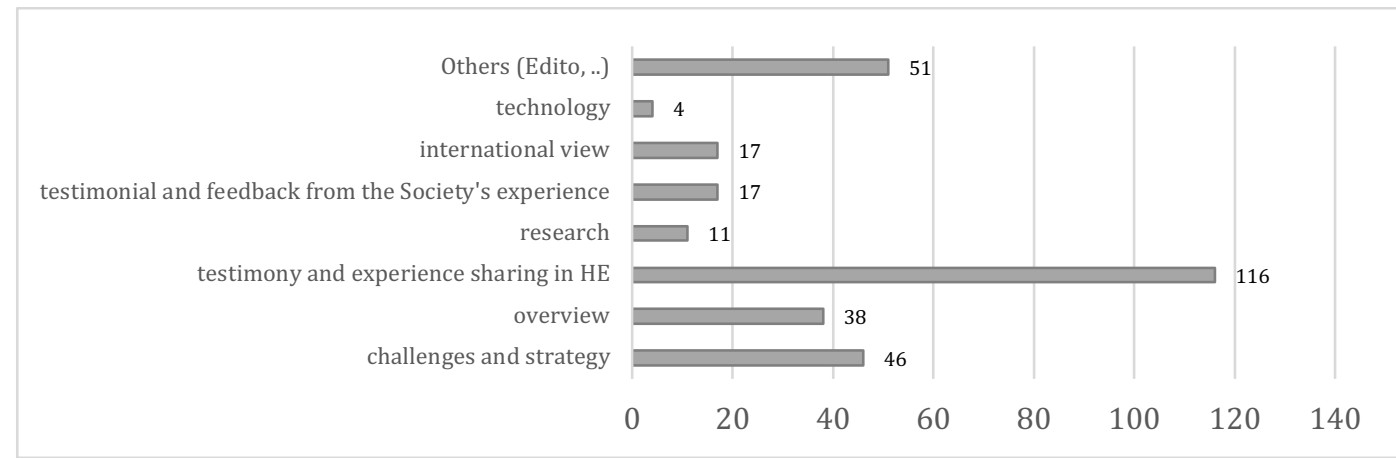

Figure 5 : Number of articles by topic 


\section{Discussions}

We would like to discuss a few points in this paragraph.

\subsection{A co-constructed communication for a community of practice}

Due to the nature of the realization of the Collection numérique, it is proposed subjects coming from the interests of the university community and whose treatment is realized by real testimonies of universities and institutions. We find a mode of operation in community of practice mixing the mutual commitment, a common enterprise organized around a shared objective, and a document shareable since in open acess.

\subsection{A mediation device for university digital technology}

As we have seen in the analysis of the issues, La Collection Numérique is one of the elements for sharing the prospective watch on digital uses in Higher Education and Research. It aims to detect them, to share testimonials that promote existing practices, and to enrich Amue's point of view on the societal, organizational, usage and technological aspects of university digital technology.

It allows the Higher Education and Research community to share their experiences and questions on the subjects covered, and to raise awareness of future issues in university digital technology: it is a base of knowledge on real cases.

La Collection numérique appears to us as an object of mediation: since Amue does not modify the authors' statements, we can consider that the Digital Collection shares different points of view on a subject in a neutral manner. It enables the linking of stakeholders on a given theme, clarifying the positions of operators.

In the survey, it appears that the respondents find knowledge on a subject and enter into understanding.

\subsection{Accompanying the stakeholders}

La Collection Numérique makes it possible, by disseminating a status report on a subject related to university digital technology, to support various stakeholders: $1 /$ The governance of institutions: To appropriate the subjects, to be sensitized, to prepare and to be helped for the next decisions on the university digital... 2 /The digital teams: to deepen the subjects, to be situated, to be inspired by the experiences of the colleagues, to identify the stakeholders,... 3/Internal Amue: In addition to the points identified above, plan for the implementation and impact of projects carried out by the Amue 4/ between universities: allow for the relationship between universities and establishments.

In the survey, both readers and authors recommend La Collection numérique, which is a great way for us to spread the word in the community. The qualifiers used to describe the quality of the articles are also noteworthy: they all have a positive connotation.

\subsection{Preparing for a desirable or desired HigherEd digital}

The initial objective of La Collection Numérique is to educate decision makers so that they can make good decisions in the digital highered. We notice that we reach our target while diffusing to all categories. The dissemination is also ensured by the authors and the readers in addition to the initial dissemination by the Amue. We believe that this sharing is an act of construction of a common HigherEd digital. 


\section{Conclusion}

In this paper, we wanted to discuss an experiment carried out in France, La Collection Numérique, which would provide a form of training for decision-makers of universities and institutions in the field of HigherEd digital. One of the main questions was how it contributes to better understand our digital?

We studied the 14 issues and conducted a survey with some readers and authors. It emerges that $\mathrm{La}$ Collection Numérique realizes well its role of mediation of the HigherEd digital, thanks to an editorial choice to involve the stakeholders of the IT of the universities and institutions but also other decision makers having set up a solution. The format, a bimonthly magazine, gives an image of quality to the magazine, as much on the form as the content. La Collection Numérique is not a communication tool of the Amue's information watch for our HigherEd community, but a device for sharing and mediation between HigherEd digital stakeholders.

Concerning the limits, we are aware that these are trends concerning the survey, which are certainly positive, but not a precise statistical study. For all that, we defend that the analysis of trends has a meaning, because the circle of decision-makers in universities and institutions is of a type that is closed to academic studies, for reasons of strategic confidentiality, not very available, and it is often difficult to convince them to spend time to answer surveys.

The perspectives are essentially to continue, but also to propose to the Eunis community, the possibility of making the articles of the issues available for translation, either within the network, or within a country that wishes to use them. But also to give the desire, within a country or our entire Eunis community, to launch another la Collection Numérique.

\section{Bibliography}

Akrich, M. (1993). Les formes de la médiation technique. 18.

Amue. (2019). La collection numérique. (S. Athanase, Éd.) à l'adresse http://www.amue.fr/systemedinformation/metier/la-collection-numerique/, ISSN 2650-8494.

Antoine, J. (1992). Un nouveau métier pour les hommes de marketing: la veille prospective et ses applications stratégiques, suivi, en annexe, de: Proposition d'un référentiel pour la veille du troisième type (sociale, culturelle et institutionnelle). Revue française du marketing, (139), 5-30.

Bachimont, B. (2010). Le sens de la technique: Le numérique et le calcul. Encres Marines

Chardel, P-A., Dartiguepeyrou, C (2018) Etre, temps et différences: pour une approche différencialiste du temps à l'ère numérique in Aubert, N (2018), @ la recherche du temps. Individus hyperconnectés, société accélérée : tensions et transformations, Toulouse, Erès Editions, 97-110.

Couzinet, V. Questions des dispositifs info-communicationnels, in Cécile Gardiès (dir.), Approche de l'information documentation : concepts fondateurs. Toulouse, Éditions Cépadues, 2011,

de Jouvenel, H. (1999). Un bref guide méthodologique. 22.

Gardiès, C. (2012). Dispositifs info-communicationnels de médiation des savoirs : cadre d'analyse pour l'information-documentation. 224.

Godet, M. (1989). Effective strategic management the prospective approach. Technology Analysis \& Strategic Management, 1(1), 45-56.

Mocquet, B. (2020). Gouvernance, numérique et enseignement supérieur. Presses des Mines.

Mucchielli, A. (1995). Les mécanismes de la médiation dans les groupes et les organisations. Introduction aux Sciences de l'Information et de la Communication, 83-93.

Peeters, H., \& Charlier, P. (1999). Contributions à une théorie du dispositif. Hermès, La Revue, (3), 15-23.

Querrien, A. (2013). Territoires et communautés apprenantes. Multitudes, $n^{\circ}$ 52(1), 45-51.

Simondon, G. (1958). Du mode d'existence des objets techniques. Aubier/Philosophie 